DOI 10.37882/2500-3682.2021.05.03

\title{
СРАВНИТЕЛЬНЫЙ АНАЛИЗ МОРАЛЬНО-НРАВСТВЕННЫХ ЦЕЛЕЙ ПОДРОСТКОВ МОСКВЫ И КАИРА
}

\section{COMPARATIVE ANALYSIS OF THE MORAL GOALS OF TEENAGERS IN MOSCOW AND CAIRO}

\section{A. Alemaeva}

Summary: The relevance of studying the life goals of adolescents lies in the fact that at this age they face the need for self-determination and choice of a future field of activity. For the first time, this article presents the results of a psychological research on the study of moral and ethical goals between high school students in Russia and Egypt in the key of meaningful orientations. The author conducted a survey in order to determine what goals modern graduates of state Moscow and Cairo set for themselves. Comparative analysis of the results showed a significant difference in values and ideals, definition of their role in society, issues of patriotism and religion. The materials obtained allow us to rethink the desires and aspirations of the younger generation, while revealing the little-studied causal dependences of the educational process in different countries. The results of this study can be used by various vocational guidance centers in schools when planning educational work.

Keywords: values, life goals, value orientations, high school students, teenager, Egypt, senior students.

\section{Введение}

A ктуальность вопроса формирования нравственных ценностей у подрастающего поколения в современных социокультурных реалиях, системе образования обусловлена тем, что в подростковом возрасте происходит активное становление самосознания личности. Этот процесс включает в себя смену интересов, развитие индивидуальных способностей и мотивационной сферы и, самое главное, нравственное развитие. Соответствие ценностных ориентаций учащихся общественным идеалам способствует становлению зрелой личности, которая взаимодействует с окружающим социумом, ищет свое место в мире и размышляет над смыслом жизни.

Изучение моральной и нравственной составляющей среди ценностных ориентаций молодежи занимались разные исследователи в области психологии и социологии. Различают несколько причин, влияющих на систему ценностей современных подростков: интернет, средства массовой информации, культура, религия, семейные установки и образовательный процесс. Однако плохо освещен вопрос, какие жизненные цели ставят подрост-
Алемаева Анна Юрьевна

Аспирант, ФГБОУ ВО «Национальный исследовательский Мордовский Государственный Университет имени Н.П. Огарева», г. Саранск

3@7a3.ru

Аннотация: Актуальность изучения жизненных целей подростков заключается в том, что в этом возрасте перед ними возникает необходимость самоопределения и выбора будущей сферы деятельности. В этой статье впервые представлены результаты психологического исследования по изучению морально-нравственных целей между старшеклассниками России и Египта в ключе смысложизненных ориентаций. Автором было проведено анкетирование с целью определить, какие цели ставят перед собой современные выпускники государственных Москвы и Каира. Сравнительный анализ итогов показал существенную разницу в ценностях и идеалах, определения своей роли в жизни общества, вопросах патриотизма и религии. Полученные материалы позволяют по-новому осмыслить желания и стремления подрастающего поколения, выявив при этом малоизученные причинные зависимости воспитательного процесса в разных странах. Результаты данного исследования могут использоваться различными профориентационными центрами, В школах при планировании воспитательной работы.

Ключевые слова: ценности, жизненные цели, ценностные ориентации, старшеклассники, подросток, Египет, старшие школьники.

ки в современных реалиях, и как вышеуказанные причины на это влияют. Чтобы дать ответы на эти вопросы, были проведены научное исследование процесса целеполагания и сравнительный анализ его итогов.

В этой статье впервые представлены результаты психологического исследования по изучению и сравнению морально-нравственных целей между старшеклассниками России и Египта в ключе смысложизненных ориентаций. Автором было проведено анкетирование учащихся старших классов с целью определить, какие цели ставят перед собой современные выпускники государственных школ столиц двух стран. По результатам исследования была обнаружена необычная закономерность, указывающая на высокий процент целей во имя общественного блага в Каире и практически полное отсутствие таковых среди анкет подростков Москвы.

В результате исследования данной проблемы автором было отмечена важная составляющая воспитательного процесса детей в семьях и образовательных учреждениях Египта. Этим неотъемлемым компонентом является патриотизм и любовь к своему Отечеству. Даже в современном обществе, когда взгляд выпускников на- 
целен на получение зарубежного высшего образования, стремления к эмиграции, прослеживается четкое стремление сделать свою страну великой, посвятить свое будущее благу народа и семьи.

Среди целей выпускников Москвы явно выражен эгоцентричный акцент в процессе целеполагания.

Данная статья показывает, какие морально-нравственные цели ставят перед собой современные выпускники мегаполисов, и в чем разница в процессе целеполагания подростков России и Египта.

\section{Анализ теоретических разработок и изученность вопроса}

Говоря о морально-нравственных аспектах в процессе целеполагания подростков, стоит изучить причинные взаимосвязи воспитания и ценностных ориентаций личности. Рассматривая воспитательный процесс в Египте, следует рассмотреть особую роль духовного воспитания подрастающего поколения. Помимо культуро-образующего воздействия на становление личности, особое значение в ориентация на жизненное предназначение и идеалы играет религиозная составляющая [4].

Понятия духовно-нравственное, нравственное и моральное воспитание отражают содержательные и ценностно-целевые векторы всего воспитательного процесса и его конечные личностные результаты [3].

Воспитание морально-нравственных ценностей современной молодежи является одной из важнейших проблем современного общества. Это обусловлено происходящими экономическими и политическими событиями внутри стран, снижением роли семьи в воспитательном процессе, девиантным и ассоциальным поведением подростков как в школах, так и в других общественных местах. Времяпрепровождение современных подростков направлено на удовлетворение личных интересов в ущерб общественным. Большинство современных российских подростков исповедуют гедонистическое мировоззрение прозападного толка. Про нравственность и нравственные принципы современные молодые люди говорят нередко в ёрническом тоне, не признавая за собой никакого нравственного долга перед государством или семьей.

В то же самое время мораль и нравственность - важнейшая составляющая духовной культуры человека.

Мораль относится к тому, как именно люди выбирают свою жизнь. Это набор руководящих принципов, которые управляют их решениями о правильном и неправильном, о добре и зле. По мере того как происходит когнитивное, эмоциональное и социальное развитие молодых людей, их понимание морали расширяется, и их поведение становится более тесно связанным с их ценностями и убеждениями. Таким образом, нравственное развитие описывает эволюцию этих руководящих принципов и демонстрирует способность применять эти руководящие принципы в повседневной жизни.

Ж. Пиаже, известный своей теорией когнитивного развития детей, также предложил теорию о нравственном развитии личности. Пиаже признавал, что когнитивное развитие тесно связано с нравственным развитием, и особенно интересовался тем, как менялись со временем представления детей о морали.

Согласно Пиаже, подрастающее поколение развивает мораль сотрудничества в возрасте 10 лет и старше. По мере того как подросток развивает мораль сотрудничества, он понимает, что для создания кооперативного общества люди должны работать вместе, чтобы решить, что приемлемо, а что нет.

Пиаже считал, что подростки в этом возрасте начинают понимать, что мораль представляет собой социальные соглашения между людьми и призвана способствовать общему благу. Кроме того, они признают, что люди могут отличаться в том, как они понимают и подходят к моральной ситуации или проблеме. Они также начинают понимать, что разница между правильным и неправильным не является абсолютной, но вместо этого надо учитывать изменяющиеся переменные, такие как контекст, мотивация, способности и намерения.

Более того, Пиаже считал, что молодежь в этом возрасте начинает понимать, что нравственность решения не зависит исключительно от результата этого решения. Например, приходит понимание, что движение по знаку «стоп» неправильно, независимо от того, получает ли человек штраф за нарушение правил дорожного движения или нет - потому что такое поведение может стать причиной дорожно-транспортного происшествия.

Кроме того, молодежь начинает понимать взаимную выгоду от принятия моральных решений, то есть моральное решение создает оптимальное решение для всех участников, даже если затрагиваются только два человека. Когда ситуация решается таким образом, который кажется справедливым, разумным и/или выгодным для всех сторон, людям становится легче принять и уважать решение.

Эта концепция справедливости называется взаимностью. Изначально юношеское понимание взаимности может быть очень буквальным и упрощенным. К среднему подростковому возрасту молодежь расширяет свое понимание справедливости, включая идеальную взаимность. Идеальная взаимность относится к типу спра- 
ведливости, выходящему за рамки простой взаимности, и включает в себя учет наилучших интересов другого человека. Это лучше всего описывается известной поговоркой: «Поступай с другими так, как ты хочешь, чтобы они поступали с тобой», которую многие люди знают, как золотое правило.

Подростки, достигшие идеальной взаимности, представляют себе проблему с точки зрения другого человека и пытаются поставить себя на его «место», прежде чем принять моральное решение.

Согласно Пиаже, как только достигается идеальная взаимность, моральное развитие завершается. Однако теперь мы знаем, что многие молодые люди будут продолжать совершенствовать свой моральный процесс принятия решений и в раннем взрослом возрасте.

Пиаже считал, что эта способность не развивается до позднего детства или ранней юности. Однако более поздние исследования показывают, что эта способность развивается быстрее, чем когда-то полагал Пиаже. Младшие дети способны осознать важность чьих-то намерений при оценке моральности того или иного решения; но младшие дети, как правило, довольно наивны в своей вере в лучшие намерения людей, которые диктуют их реальный выбор.

Подростки должны ежедневно выносить моральные суждения. Когда дети младше, их семья, культура и религия сильно влияют на принятие ими моральных решений. Однако в раннем подростковом периоде сверстники оказывают гораздо большее влияние. Давление сверстников может оказать сильное влияние, потому что друзья играют более значительную роль в жизни подростков. Более того, развивающаяся способность мыслить абстрактно позволяет молодежи осознать, что предписываемые правила созданы другими людьми. В результате подростки начинают сомневаться в абсолютной власти родителей, школ, правительства и других традиционных институтов. Скептицизм и бунт против «традиционных ценностей» свойственны многим подросткам просто в силу возраста. Одновременно происходит снижение интереса к учебе в угоду тому, что интересно для подростка в данный момент [1].

К концу подросткового возраста большинство подростков становятся в большей степени конформистами и признают ценности общества, поскольку они начинают устанавливать свою собственную идентичность, свою собственную систему убеждений и свое собственное место в мире.

Некоторые молодые люди, стремящиеся достичь самых высоких уровней морального развития, могут реализовать свои убеждения на практике. Это выражается в том, что они принимают участие в деятельности, демонстрирующей их моральные убеждения. Например, некоторые студенты колледжа могут организовывать и участвовать в демонстрациях и протестах, в то время как другие студенты могут добровольно посвятить свое время проектам, которые продвигают этические принципы, важные и ценные для этих молодых людей.

К сожалению, у некоторых молодых людей есть негативный жизненный опыт, который может помешать их нравственному развитию. Возможно, они пережили какой-то травматический опыт или разочарование в своих идеалах. В молодом возрасте такие вещи воспринимаются весьма болезненно. Такие переживания могут заставить подростков и молодежь рассматривать весь мир как безнравственный и несправедливый. Или, возможно, они наблюдали, как взрослые в своей жизни принимали аморальные решения, которые игнорировали права и благополучие других, приводя этих молодых людей к развитию убеждений и ценностей, которые противоречат остальному обществу. Не имея морального компаса, эти молодые люди могут никогда не достичь своего полного потенциала и могут столкнуться с трудностями в формировании значимых и полезных отношений с другими.

Таким образом, хотя процесс нравственного развития может быть трудным или сложным, важно помнить, что этот этап развития необходим для благополучия и успеха в жизни.

В 2015 году Председатель Правительства Российской Федерации Д. Медведев подписал Стратегию развития воспитания в Российской Федерации на период до 2025 года [5]. В данной стратегии перечислены элементы духовно-нравственных ценностей, таких как человеколюбие, стремление к исполнению нравственного долга перед самим собой, своей семьей и своим Отечеством. Среди основных направлений развития отмечено обновление воспитательного процесса с учетом современных достижений науки на основе отечественных традиций. Его элементами являются гражданское и патриотическое воспитание, духовно-нравственное развитие, а также приобщение детей к культурному развитию.

Ранее проведенные социологические исследования морально-нравственных ориентаций современной российской молодежи показали, что ведущими являются индивидуальные ценности, а общественные принимаются, но не в ущерб личным [2].

\section{Методология.}

\section{Контекст исследования}

В состав методов, обеспечивающих проведение дан- 
ной работы, входили: теоретический анализ источников, социологическое исследование (опрос), методы математической статистики.

В проведенном исследовании были использованы данные по результатам анкетирования подростков.
В исследовательских целях старшеклассников Москвы и Каира попросили заполнить анкеты.

\section{Выборка}

В соответствии с поставленной целью и задачами в сравнительном психологическом исследовании с 2017г.

Группы и подгруппы целей

\begin{tabular}{|c|l|l|}
\hline \multicolumn{1}{|c|}{ Основныне группы целей } & \multicolumn{1}{|c|}{ Подгруппы целей, включенные в основную группу } \\
\hline 1 & Авто & Получение водительских прав, приобретение автомобиля \\
\hline 2 & Другое & Не включенное в остальные категории \\
\hline 3 & Друзья & Друзья, отношения \\
\hline 4 & Здоровье & Красота \\
\hline 5 & Иностранные языки & \\
\hline 6 & Любовь & Партнеры \\
\hline 7 & Учеба & Образование, знания, навыки, умения \\
\hline 8 & Отдых & Развлечения, комфорт, счастье \\
\hline 9 & Покупки & Накопления \\
\hline 10 & Путешествия & \\
\hline 11 & Карьера & Профессии, успех \\
\hline 12 & Религия & Благотворительность, патриотизм \\
\hline 13 & Самообразование & Предназначение, личностный рост \\
\hline 14 & Семья & Родственники, домашние питомцы, домашние заботы \\
\hline 15 & Спорт & \\
\hline 16 & Хобби & \\
\hline
\end{tabular}

Распределение целей по основным жизненным сферам

\begin{tabular}{|l|c|c|l|c|c|}
\multicolumn{1}{c|}{$\begin{array}{c}\text { Основные группы } \\
\text { целей }\end{array}$} & Москва & $\begin{array}{c}\text { Оот общего } \\
\text { количества целей }\end{array}$ & $\begin{array}{c}\text { Основные группы } \\
\text { целей }\end{array}$ & Каир общего \\
Автоличества целей
\end{tabular}


по 2020г. было задействовано 200 старшеклассников мужского и женского пола в возрасте от 14 до 18 лет. Вся выборка была разделена на две группы для сравнения. Первую группу составили 100 старшеклассников мегаполиса Москва из школ №№ 49, 311, 1065, 1191, 1985.

Вторую группу составили 100 старшеклассников из столицы Египта города Каира. Испытуемыми являлись старшеклассники - учащиеся 9-11 классов.

\section{Результаты}

Каждому учащемуся было предложено написать 10 актуальных для него жизненных целей.

По результатам статистической обработки общее количество целей, подлежащих анализу составило 1440: 738 целей у подростков Москвы и 732 цели у подростков Каира

Результаты анкетирования были разбиты на 16 условных категорий сфер жизни. Цели были классифицированы по следующим группам, объединяющие подгруппы целей.

В таблице 3 представлено распределение целей по рангам.

Полученные результаты указывают на наличие стати- стически значимых различий в целях подростков в представленной выборке. Так из 16 основных жизненных сфер подростки Каира среди своих целей уделяют большое значение вопросам: карьеры (29\%); учебы (12,4\%); путешествий (11,3\%); самообразования $(11,1 \%) ;$ религии $(10,7 \%)$.

В то время как для столичных школьников России важными являются вопросы: учебы (29,1\%); отдыха (14,4\%); семьи $(9,5 \%)$; здоровья $(8,80 \%) ;$ хобби (7,90\%).

Самообразование в рейтинге московских подростков выбрали всего 3,50\% опрошенных, религию не выбрал никто из опрошенных.

Однако для того, чтобы сделать вывод о разнице морально-нравственных целей между подростками Москвы и Каира, вышеуказанной классификации недостаточно. Выделим группы целей с различным уровнем.

Далее на рисунке 1 представлена сравнительная диаграмма ценностей московских и каирских подростков.

Мы отмечаем ориентацию молодежи на рыночные и личные ценности в ущерб общественным.

Результаты показывают существенную разницу жизненных целей подростков Каира и Москвы.

Таблица 3.

Распределение целей по рангам

\begin{tabular}{|c|c|c|c|c|c|}
\hline $\begin{array}{c}\text { Основные группы } \\
\text { целей }\end{array}$ & Москва & $\begin{array}{c}\text { \% от общего } \\
\text { количества целей }\end{array}$ & $\begin{array}{c}\text { Основные группы } \\
\text { целей }\end{array}$ & Каир & $\begin{array}{c}\text { \% от общего } \\
\text { количества целей }\end{array}$ \\
\hline Учеба & 215 & $29,10 \%$ & Карьера & 212 & $29,00 \%$ \\
\hline Отдых & 106 & $14,40 \%$ & Учеба & 91 & $12,40 \%$ \\
\hline Семья & 70 & $9,50 \%$ & Путешествия & 83 & $11,30 \%$ \\
\hline Здоровье & 65 & $8,80 \%$ & Самообразование & 81 & $11,10 \%$ \\
\hline Хобби & 58 & $7,90 \%$ & Религия & 79 & $10,70 \%$ \\
\hline Покупки & 44 & $6,00 \%$ & Семья & 51 & $6,90 \%$ \\
\hline Карьера & 42 & $5,70 \%$ & Авто & 45 & $6,20 \%$ \\
\hline Путешествия & 40 & $5,40 \%$ & Покупки & 21 & $2,90 \%$ \\
\hline Самообразование & 26 & $3,50 \%$ & Хобби & 17 & $2,40 \%$ \\
\hline Иностранные языки & 21 & $2,80 \%$ & Иностранные языки & 15 & $2,00 \%$ \\
\hline Друзья & 18 & $2,40 \%$ & Спорт & 15 & $2,00 \%$ \\
\hline Любовь & 11 & $1,50 \%$ & Друзья & 7 & $0,90 \%$ \\
\hline Авто & 10 & $1,40 \%$ & Здоровье & 7 & $0,90 \%$ \\
\hline Другое & 9 & $1,20 \%$ & Другое & 5 & $0,70 \%$ \\
\hline Спорт & 3 & $0,40 \%$ & Любовь & 3 & $0,40 \%$ \\
\hline Религия & 0 & $0,00 \%$ & Отдых & 1 & $0,20 \%$ \\
\hline итого: & 738 & & итого: & 732 & \\
\hline
\end{tabular}


Таблица 4.

Ценностные ориентации подростков России и Египта.

\begin{tabular}{|l|c|c|l|c|c|}
\multicolumn{1}{|c|}{ Ценностные ориентации } & Москва & $\begin{array}{c}\text { \% от общего } \\
\text { количества целей }\end{array}$ & \multicolumn{1}{c|}{ Ценностные ориентации } & $\begin{array}{c}\text { К от общего } \\
\text { количества целей }\end{array}$ \\
\hline $\begin{array}{l}\text { Высокое материальное } \\
\text { положение }\end{array}$ & 267 & $36,18 \%$ & $\begin{array}{l}\text { Высокое материальное } \\
\text { положение }\end{array}$ & 212 & $28,96 \%$ \\
\hline Служение обществу & 18 & $2,44 \%$ & Служение обществу & 165 & $22,54 \%$ \\
\hline Достижения & 70 & $9,49 \%$ & Достижения & 191 & $26,09 \%$ \\
\hline $\begin{array}{l}\text { Сохранение собственной } \\
\text { идентичности }\end{array}$ & 182 & $24,66 \%$ & $\begin{array}{l}\text { Сохранение собственной } \\
\text { идентичности }\end{array}$ & 81 & $11,07 \%$ \\
\hline Получение удовольствий & 201 & $27,24 \%$ & Получение удовольствй & 83 & $11,34 \%$ \\
\hline
\end{tabular}

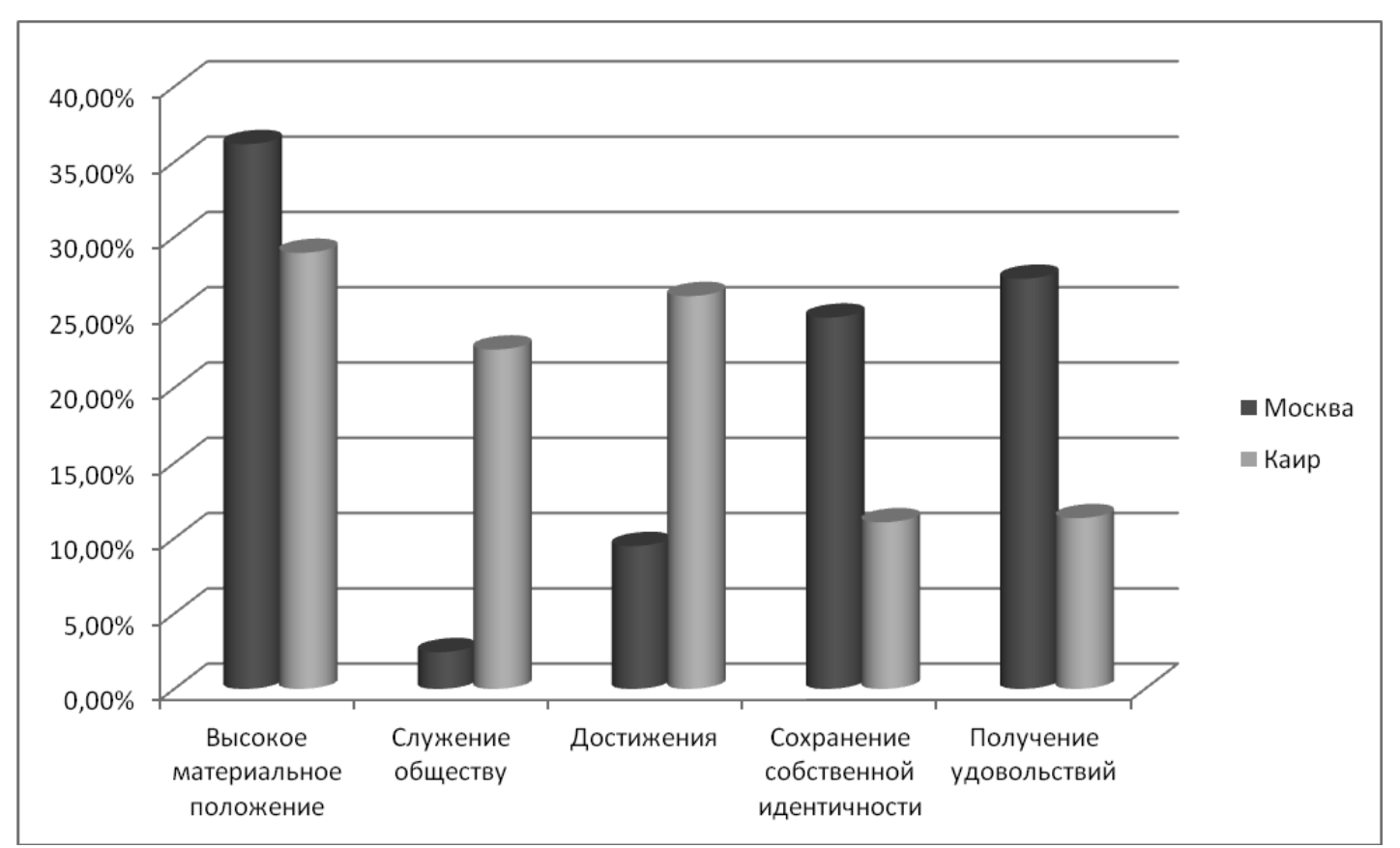

Рис. 1. Ценности московских и каирских подростков

Старшеклассники Каира ставят цели преимущественно в категории Карьеры с последующей эмиграцией из страны.

Старшеклассники Москвы ориентируют свое целеполагание в поле дальнейших выпускных экзаменов в школе и поступлении в ВУЗ.

\section{Выво $\Delta ы$}

Проведенное исследование позволило оценить разницу в нравственно-моральных ценностях подростков разных стран. Полученные в результате анализа анкетирования данные позволяют установить, что подростки Москвы и подростки Каира имеют отличные цели и ценностные ориентации.

\section{Ограничения исследования}

В исследовании принимали участие старшеклассни- ки столиц России и Египта. Ограниченность исследования выражается в нескольких факторах:

Исследовались учащиеся государственных школ с бесплатным образованием. При этом в Каире средний социальный класс и обеспеченные люди стараются отдавать своих детей в международные школы Каира. Предполагается, что сфера интересов и жизненных целей у данной категории населения будет отличаться.

В исследовании не принимали участие школьники из отдаленных регионов обоих стран.

Исследование проводилось лишь среди школьников выпускных классов возраста 14-18 лет. Младшие школьники в исследовании не участвовали.

Гипотеза исследования о различии ценностных и нравственных ориентаций подростков Каира и Москвы подтвердилась. 


\section{Направления Аальнейших исследований}

Учесть в исследованиях коммерческие школы, отдаленные регионы, школьников более младшего возраста. Увеличить выборку участников исследования.

Изучить распределение результатов на долгосрочные и краткосрочные цели. Провести анализ и интер- претацию.

Возможности практического или теоретического применения результатов вашей статьи.

Данные исследования позволяют разрабатывать методики и программы развития навыков целеполагания с учетом важности религиозного компонента, эмиграционной проблемы и масштабов целей.

\section{ЛИТЕРАТУРА}

1. Алемаева А.Ю. Уровни ценностей у старшеклассников: безопасность и интерес //Человек и современный мир. 2018. № 10 (23). С. 55-61.

2. Вишнякова Н.А., Долгаева Е.И. Морально-нравственные ориентации современной молодежи // Вестник МГУ. 2011. № 3. С. $222-225$.

3. Гусакова В.0. 0 духовно-нравственном, нравственном и моральном воспитании // Вестник ЮУрГГПУ. 2015. № 3. С. 90-99.

4. Овчарова Р.В. Моральные ценности и подростковая делинквентность // Вестник Курганского государственного университета. 2015. № 2 (36). С. 65-76.

5. Распоряжение Правительства Российской Федерации от 29 мая 2015 г. № 996-р г. Москва «Стратегия развития воспитания в Российской Федерации на период до 2025 года» [Электронный ресурс] // Российская газета - Федеральный выпуск № 122(6693). Режим доступа: https://rg.ru/2015/06/08/ vospitanie-dok.html (дата обращения: 10.01.2021).

(c) Алемаева Анна Юрьевна (3@7а3.ru).

Журнал «Современная наука: актуальные проблемы теории и практики»

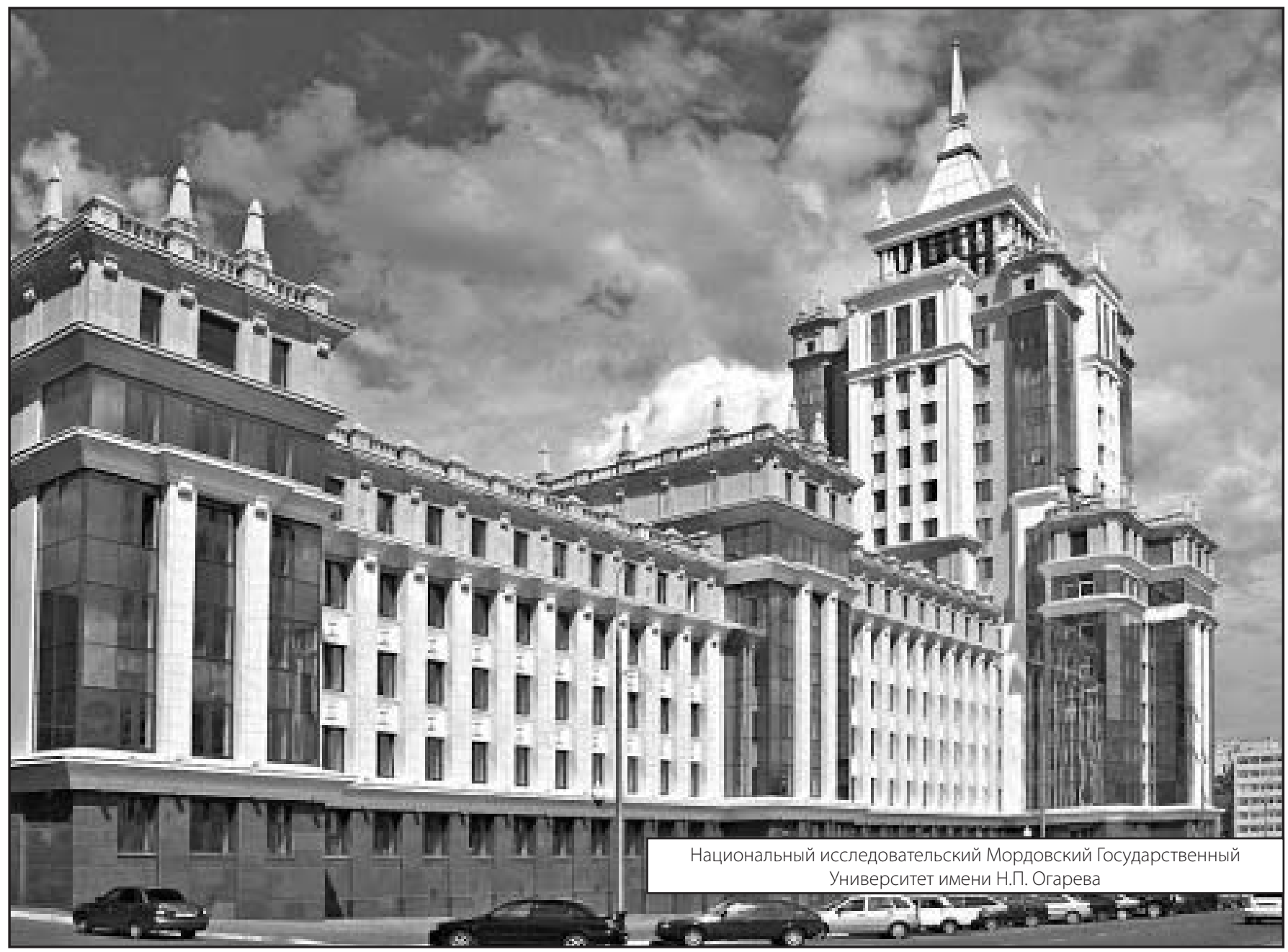

